\title{
Antioxidant and antibacterial activities of fruit extracts of Berberis species from Nepal
}

\author{
Sarala Dhungel, Giri Prasad Joshi and Deepak Raj Pant* \\ Central Department of Botany, Tribhuvan University, Kirtipur, Kathmandu, Nepal
}

\begin{abstract}
The Himalayan region is rich in flowering plants diversity, including medicinal and wild edible plants. These plants possess variety of therapeutically important compounds, like alkaloids, flavonoids, phenolics, saponins, steroids, tannins and terpenoids in different parts. Presence of significant amount of these compounds makes a species valuable to be used as super foods or medicines. Furthermore, plant extracts especially those of fruits are basically attributed with natural antioxidants, either in form of vitamins or color-inducing pigments, which have become the target to replace the synthetic antioxidants. In this regard, fruits of Berberis species, one of the popular wild edible fruits of Nepal, are noted for their antioxidant property since time immemorial. The present study was done with an attempt to quantify the antioxidant potential and antibacterial activities of the fruit extracts of four taxa of Berberis ( $B$. angulosa var. angulosa, B. angulosa var. fasciculata, B. aristata and B. asiatica) from Nepal and to correlate the antioxidant potential with various phytochemicals present in the extracts. Methanolic fruit extracts were used to spectrophotometrically quantify total phenolic and flavonoid contents. DPPH free radical scavenging assay and antibacterial assay were carried out in in-vitro condition. Preliminary phytochemical analysis revealed high polyphenol content $(52.60 \pm 3.73$ and $58.07 \pm 1.44 \mathrm{mg} \mathrm{GAE} / \mathrm{g}$ ) and better antioxidant property $(35.29 \pm 3.01$ and $29.15 \pm 2.01 \mu \mathrm{g} / \mathrm{ml})$ respectively in $B$. angulosa var. angulosa and B. angulosa var. fasciculata than in the fruit extracts of $B$. aristata and $B$. asiatica. In contrast, fruit extracts of $B$. asiatica showed the highest total flavonoid content $(27.52 \pm 0.56 \mathrm{mg} \mathrm{QE} / \mathrm{g})$ than did by the extracts of other taxa studied. The fruit extract of B. aristata and $B$. angulosa var. fasciculata at very high concentration $(200 \mathrm{mg} / \mathrm{ml})$ showed maximum zone of inhibition (ZOI) against tested bacterial strains, Staphylococcus aureus and Escherichia coli. In contrast, B. asiatica did not show any ZOI for both of the tested bacterial strains. As fruits are better sources of antioxidant with greater accumulation of flavonoids and phenolics, wild fruits should be equally spaced for their better efficiency as cultivated ones.
\end{abstract}

Key-words: Berberis species, antioxidant, antibacterial, phytochemical analysis.

\section{Introduction}

Fruits are one of the major components of balanced diet as they supply humans with very important nutrients, like sugar, vitamins, anthocyanins and dietary fibers. For this reason, people usually grow commercial fruits in their fields for family consumption or as a sort of family earning. In addition to the commercial fruits, there are certain fruits that are freely available in the wild which are usually not sold in the market but are consumed by the local population. The wild edible fruits play a significant role in human nutrition, especially in the rural areas where they are only sources of edible fruits that the people can afford. Fruits of different species of Berberis are among the most important wild edible fruits of Nepal. These fruits are reported to be rich in various phytochemicals and exhibit antioxidant (Andola et al. 2008; Hanachi et al. 2006; Chandra et al. 2011), antimicrobial (Chandra et al. 2011; Dashti et al. 2014), antidiabetic (Rajaei et al. 2011; Meliani et al. 2011), hepatoprotective (Eidi et al. 2011), antihistaminic and anticholinergic (Shamsa et al. 1999) activities. Literature reveals that fruits of Berberis spp. possess higher levels of total polyphenols, catechins and ascorbic acid (Pal et al. 2013), significant presence of flavonoid and polyphenols (Chandra et al. 2011) and alkaloids (Kamal et al. 2011). However, Nepalese species of Berberis are not well studied from these perspectives. Therefore, the present study focuses on phytochemical characterization of Berberis spp. of Nepal to substantiate their use as alternative food source. More specifically, the aims of the study are to quantify the antioxidant potential and antibacterial activities of the fruit extracts of four taxa of Berberis (B. angulosa var. angulosa, $B$. angulosa var. fasciculata, $B$. aristata and B. asiatica) and to correlate the antioxidant potential with various phytochemicals present in the extracts.

\section{Materials and Methods}

\section{PLANT MATERIALS}

Fresh fruits of four taxa of Berberis were collected from their wild habitats in Nepal. They were then carefully purged of any branches, thorns, leaves, mud, seeds and other waste 
substances and were air dried at $30-35^{\circ} \mathrm{C}$. The voucher specimen of each taxon was collected and later deposited at the Tribhuvan University Central Herbarium (TUCH).

\section{PREPARATION OF FRUIT EXTRACTS}

The dried fruits were carefully excised to remove seeds and pulp was then ground to fine powder using an electric blender. Ten grams of powdered pulps were then extracted with $100 \mathrm{ml}$ of methanol (Thermo Fisher Scientific, India) by using ultrasonic wave at $30 \mathrm{~W}$ in UC-7240BDT sonicator (EchromeTech, Taiwan). The extracts were separately evaporated to dryness under reduced pressure. The dried extracts were then used for experiments.

\section{TOTAL POLYPHENOL CONTENT DETERMINATION}

Total polyphenol content was determined by folin-ciocalteu method (Ainsworth and Gillespie 2007) with slight modification. One milliliter of 1:10 dilution of Phenol Ciocalteu reagent (Thermo Fisher Scientific, India) was mixed with $100 \mu \mathrm{l}$ of plant extract $(2.5 \mathrm{mg} / \mathrm{ml})$ and $800 \mu \mathrm{l}$ of $1 \mathrm{M}$ aqueous $\mathrm{Na}_{2} \mathrm{CO}_{3}$ (Merck India Ltd, Mumbai) solution. The reaction mixture was allowed to stand for 15 minutes at room temperature and the mixture was then subjected to absorbance measurement at 765 $\mathrm{nm}$ in spectrophotometer (CT8600, EChrome Tech, Taiwan). The blank was prepared in the same manner but using $100 \mu \mathrm{l}$ pure methanol in place of fruit extracts. Gallic acid solution in methanol and water $(50: 50 \mathrm{v} / \mathrm{v})$ in the concentration range 25 to $250 \mu \mathrm{g} / \mathrm{ml}$ was used as standard. The total phenolic content was measured as gallic acid equivalent (GAE) per gram of dry mass (mg GAE/gm).

\section{TOTAL FLAVONOID CONTENT DETERMINATION}

Total flavonoid content was estimated by aluminium chloride colorimetric method as per Roy et al. (2011). Standard quercetin (Sigma Aldrich, Germany) in the range of 10 to $100 \mu \mathrm{g} / \mathrm{ml}$ was prepared in methanol. Similarly, the fruit extracts were prepared in methanol at a concentration of 10 $\mathrm{mg} / \mathrm{ml}$. Two hundred fifty $\mu \mathrm{l}$ of each of fruit extracts and quercetin standards of different concentration were taken in separate test tubes and then mixed with $50 \mu \mathrm{l}$ of $10 \% \mathrm{AlCl}_{3}$ (Thermo Fisher Scientific, India), $50 \mu \mathrm{l}$ of $1 \mathrm{M}$ potassium acetate (Thermo Fisher Scientific, India), and $1.4 \mathrm{ml}$ of distilled water. The mixture was well shaken and left for 30 minutes at room temperature. The mixture was then subjected to absorbance measurement at $415 \mathrm{~nm}$ in spectrophotometer (CT8600, EChrome Tech, Taiwan). The blank was prepared in the same manner but using pure methanol in place of plant extracts and standard quercetin. The total flavonoid content was expressed as milligrams of quercetin equivalent per gram of dry mass (mg QE/g).

\section{DETERMINATION OF ANTIOXIDANT ACTIVITY}

Antioxidant activity of fruit extracts was carried out by using 1, 1-Diphenyl-2-picrylhydrazyl (DPPH) following the protocol of Singh et al. (2002) with slight modification. Different concentrations of fruit extracts and standard ascorbic acid in the range of 10 to $100 \mu \mathrm{g} / \mathrm{ml}$ were prepared in methanol. One milliliter of each sample (extract or ascorbic acid of different concentrations) was taken and separately mixed with $1 \mathrm{ml}$ of $0.2 \mathrm{M}$ DPPH in $2 \mathrm{ml}$ polypropylene tubes with proper shaking. The tubes were allowed to stand in dark for 30 minutes at room temperature. The control was prepared in the same manner but contained pure methanol instead of fruit extracts or ascorbic acid. The absorbance was measured at $517 \mathrm{~nm}$ in UV-Visible Spectrophotometer (CT8600, EChrome Tech, Taiwan) using methanol as blank. The inhibitory percentage of DPPH ( $\%$ radical scavenging activity) was calculated as:

$\%$ Radical scavenging activity $=100 *$ (Control Absorbance - Sample Absorbance) / Control Absorbance

\section{ANTIBACTERIAL ACTIVITIES}

Antibacterial activity of fruit extracts was determined by using Agar well diffusion method as described in Perez et al. (1990). Six wells were prepared on the solid Mueller Hinton Agar (Himedia Ltd., Mumbai) media with the help of sterile cork borer of $5 \mathrm{~mm}$ diameter and labeled properly with the permanent marker pen. Five different concentrations $(200 \mathrm{mg} /$ $\mathrm{ml}, 150 \mathrm{mg} / \mathrm{ml}, 100 \mathrm{mg} / \mathrm{ml}, 50 \mathrm{mg} / \mathrm{ml}$ and $0 \mathrm{mg} / \mathrm{ml}$ ) of the fruit extracts were prepared in DMSO. Sterile filter paper discs were placed inside the agar wells except one. With the help of sterile micropipette, $25 \mu \mathrm{l}$ of each individual fruit extract was poured in the above prepared well. The gentamycin discs containing $10 \mu \mathrm{g}$ of antibiotics were taken as the positive control. The plates were then scrubbed with cotton swab containing the inoculums of either of the bacterial strains (Escherichia coli or Staphylococcus aureus) to make a confluent lawn on the media surface. The plates were incubated overnight at $37^{\circ} \mathrm{C}$ and the zone of inhibition was observed and noted for individual fruit extracts of individual bacteria for different concentration for further analysis.

\section{STATISTICAL ANALYSIS}

All the experiments were performed in triplicates for each sample and values were reported as mean \pm SD. One-way analysis of variance was used to find out the statistical significance of the differences in mean values of different parameters. All the statistical analyses were done using Microsoft Excel 2010. 


\section{Results}

\section{TOTAL PHENOLIC CONTENT}

The total phenolic content of fruit extracts of different taxa of Berberis is shown in Figure 1. The highest total phenolic content $(58.07 \pm 1.44 \mathrm{mg} \mathrm{GAE} / \mathrm{g})$ was found in $B$. angulosa var. fasciculata while the lowest content $(46.47 \pm 0.50 \mathrm{mg}$ GAE/g) was found in B. aristata. The total phenolic content in other species had values intermediate between these two extremes. The differences in mean values of total phenolic content in fruit extracts of different taxa of Berberis were statistically significant $(P \leq 0.05)$.

\section{TOTAL FLAVONOID CONTENT}

The total flavonoid content of fruit extracts of different taxa of Berberis is shown in Figure 2. The highest total flavonoid content $(27.52 \pm 0.56 \mathrm{mg} \mathrm{QE} / \mathrm{g})$ was found in $B$. asiatica while the lowest content $(26.16 \pm 0.28 \mathrm{mg} \mathrm{QE} / \mathrm{g})$ was found in B. angulosa var. fasciculata. The total flavonoid content in fruit extracts of other taxa had values intermediate between these two extremes. The differences in mean values of total phenolic content in fruit extracts of different taxa of Berberis were statistically insignificant $(P \leq 0.05)$.

\section{RADICAL SCAVENGING ACTIVITY OF FRUIT EXTRACTS}

The antioxidant activity of fruit extracts of different taxa of Berberis in terms of $\mathrm{IC}_{50}$ value of DPPH radical scavenging activity is shown in Figure 3. The fruit extracts of all taxa studied had $\mathrm{IC}_{50}$ values much higher than that of ascorbic acid. Among the plant extracts, the lowest $(29.15 \pm 2.01 \mu \mathrm{g} / \mathrm{ml})$ and the highest $(90.73 \pm 1.91 \mu \mathrm{g} / \mathrm{ml}) \mathrm{IC}_{50}$ value was observed for B. angulosa var. fasciculata and B. asiatica, respectively. The differences in mean values of $\mathrm{IC}_{50}$ in fruit extracts of different taxa were statistically significant $(P \leq 0.05)$. The $\mathrm{IC}_{50}$ value of fruit extracts of different taxa of Berberis showed negative correlation with total phenolic content and positive correlation with total flavonoid content (Figure 4).

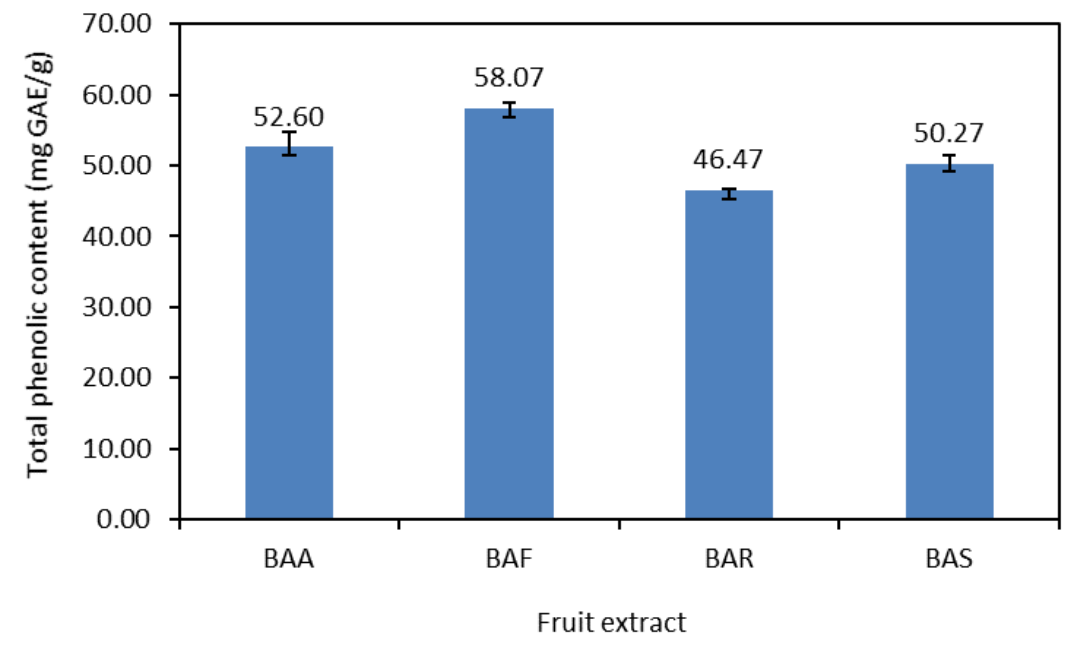

Figure 1. Total phenolic content (TPC) of fruit extracts of different taxa of Berberis (BAA - B. angulosa var. angulosa, BAF - B. angulosa var. fasciculata, BAR - B. aristata, BAS - B. asiatica).

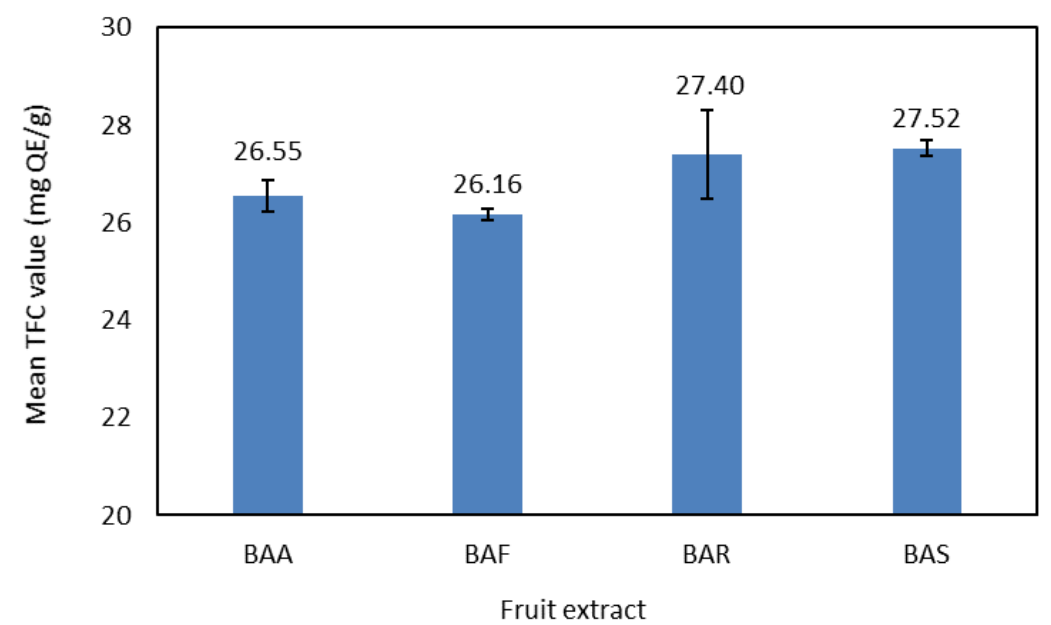

Figure 2. Total flavonoid content (TFC) of fruit extracts of different taxa of Berberis (BAA - B. angulosa var. angulosa, BAF - B. angulosa var. fasciculata, BAR - B. aristata, BAS - B. asiatica). 


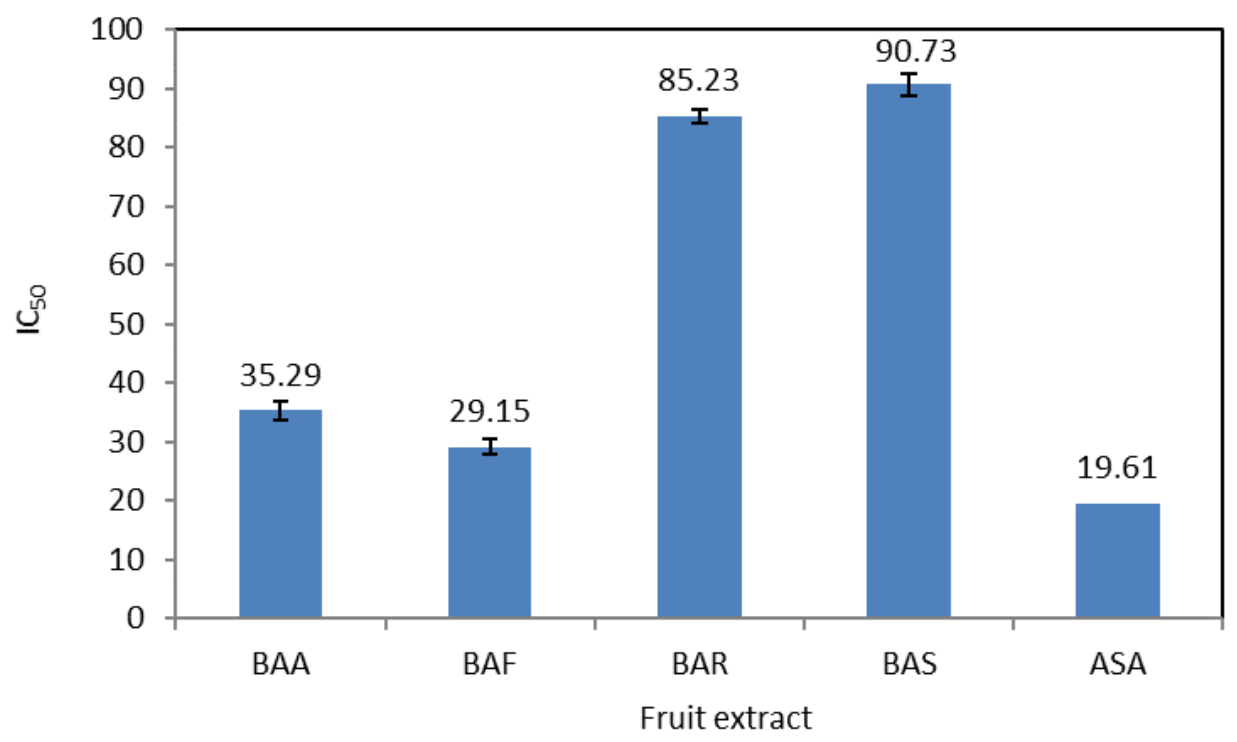

Figure 3. $\mathrm{IC}_{50}$ value of fruit extracts of different taxa of Berberis (BAA - B. angulosa var. angulosa, BAF - B. angulosa var. fasciculata, BAR - B. aristata, BAS - B. asiatica). ASA - Ascorbic acid.
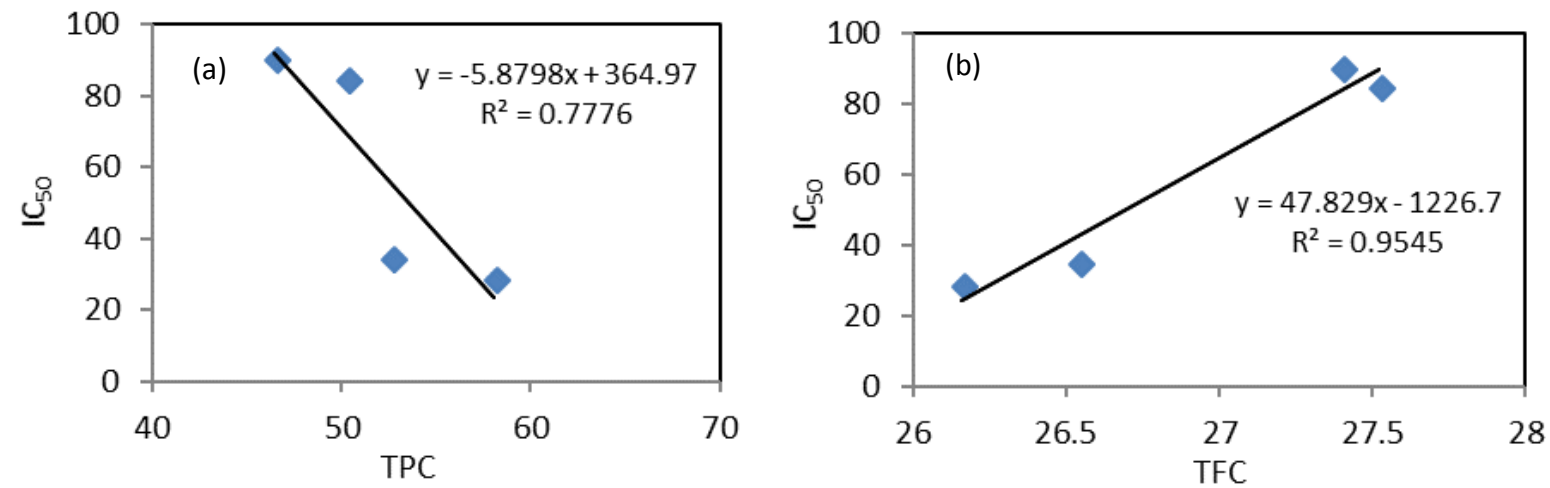

Figure 4. Relationship of $\mathrm{IC}_{50}$ value with (a) total phenolic content (TPC) and (b) total flavonoid content (TFC).

\section{ANTIBACTERIAL ACTIVITY}

The fruit extracts of different taxa of Berberis were found to exhibit very weak antibacterial activity against both the bacterial strains tested even at a concentration of $5 \mathrm{mg}$ per disc (i.e., 500 times the concentration of positive control, gentamicin). Fruit extracts of B. angulosa var. angulosa, $B$. angulosa var. fasciculata and B. aristata showed antibacterial activity against both bacterial strains at high concentration of the extract. The effects were higher against $S$. aureus compared to $E$. coli. The extracts of $B$. asiatica did not show antibacterial activity at any tested concentration (Table 1 ).

\section{Discussion}

Wild edible fruits are considered good sources of phenolic compounds, including polyphenols. The main polyphenol classes of compounds in berries are flavonoids (anthocyanins, flavonols and flavanols), condensed and hydrolyzable tannins, stilbenoids (resveratrol), and phenolic acids (Seeram 2008).
Phenolic compounds have a determinant role in taste formation and they contribute to astringency and bitterness. Phenolics are among the widely available chemicals in fruits and particularly known for their preventive activity against reactive oxygen species and free radicals (Saini et al. 2014).

The phenolic content reported in fruit extracts of different species of Berberis are quite variable and lie in the range of 280 $\mathrm{mg} \mathrm{GAE} / \mathrm{g}$ fruit extract in B. vulgaris (Motalleb et al. 2005) to $6.7 \mathrm{mg} \mathrm{GAE} / \mathrm{g}$ in B. asiatica (Chandra et al. 2011). The range of total phenolic content in the fruit extracts of different taxa of Berberis selected in present study are much higher than the values reported by Chandra et al. (2011) and lower than that reported by Mottleb et al. (2005). The differences in the values of total phenolic content can be attributed to the differences in species, extraction procedure, extraction medium and quantification technique.

Flavonoids are one of the phenolic compounds that account for the antioxidant property of plant extracts, including 
Table 1. Antibacterial activity of fruit extracts of different taxa of Berberis

\begin{tabular}{|c|c|c|c|c|c|c|c|}
\hline \multirow{2}{*}{$\begin{array}{l}\text { Fruit } \\
\text { extract* }\end{array}$} & \multirow{2}{*}{ Bacterial culture } & \multicolumn{6}{|c|}{ Zone of inhibition in different samples (mm) } \\
\hline & & 50 & 100 & 150 & 200 & Gen10** & DMSO \\
\hline \multirow[t]{2}{*}{ BAA } & S. aureus & - & - & $9.0 \pm 0.57$ & $10.0 \pm 0.88$ & $25.0 \pm 1.60$ & - \\
\hline & E. coli & - & - & - & $7.0 \pm 0.39$ & $24.0 \pm 1.53$ & - \\
\hline \multirow[t]{2}{*}{ BAF } & S. aureus & - & $8.0 \pm 0.00$ & $11.0 \pm 0.89$ & $12.0 \pm 0.65$ & $25.0 \pm 1.60$ & - \\
\hline & E. coli & - & - & $7.0 \pm 0.66$ & $8.0 \pm 0.50$ & $24.0 \pm 1.53$ & - \\
\hline \multirow[t]{2}{*}{ BAR } & S. aureus & $7.0 \pm 0.46$ & $9.0 \pm 0.75$ & $11.0 \pm 0.87$ & $13.0 \pm 1.38$ & $25.0 \pm 1.60$ & - \\
\hline & E. coli & - & & $8.0 \pm 0.33$ & $10.0 \pm 0.54$ & $24.0 \pm 1.53$ & - \\
\hline \multirow[t]{2}{*}{ BAS } & S. aureus & - & - & - & - & $25.0 \pm 1.60$ & - \\
\hline & E. coli & - & - & - & - & $24.0 \pm 1.53$ & - \\
\hline
\end{tabular}

*BAA - B. angulosa var. angulosa, BAF - B. angulosa var. fasciculata, BAR - B. aristata, BAS - B. asiatica.

**Gen10 - gentamycin $10 \mu \mathrm{g}$.

those of fruits. Anthocyanins are the most common flavonoids in fruits and are responsible for blue red or violet coloration in berries (Yao et al. 2004). Flavonoids have received considerable attention because of antioxidants, which are useful in the prevention of cancer and cardiovascular diseases, and some pathological disorders of gastric and duodenal ulcers, allergies, vascular fragility, and viral and bacterial infections (Rosenberg Zand et al. 2002). The positive correlation between the antioxidant activity and total flavonoid content in present study are in good agreement with Rosenberg Zand et al. (2002).

Berberine, a protoberberine alkaloid, is the active ingredient present in significant quantities in different parts of Berberis species. Berberine is implicated in a number of medicinal applications, like antioxidant, antimicrobial, antidiabetic, hepatoprotective and antihyperglycemic activities (Soffar et al. 2001; Semwal et al. 2009; Singh and Kakkar 2009; Koncic et al. 2010; Tiwari and Khosa 2010). Berberine content is reported to be higher in roots than in stem and leaves (Andola 2012). Beberine has also been reported to be present, though to a lesser extent, in fruit extracts of B. aristata and $B$. asiatica (Kamal et al. 2011; Chandra et al. 2011).

The presence of rich amount of phenolics, including flavonoids in the fruit extracts of Berberis and their good antioxidant activity as shown in the present study make the Berberis fruits an ideal source of locally available natural antioxidants which can be used for improving the health conditions of rural people. The weak antibacterial activity of fruit extracts substantiates the earlier findings and supports the use of these wild edible fruits, especially those of $B$. asiatica for human consumption even in relatively large quantities without having any negative impact on beneficial microflora inhabiting the human gut.

\section{Acknowledgements}

The authors are thankful to UGC Nepal for providing the financial support to carry out this research. The authors are grateful to Department of National Parks and Wildlife Reserves (DNPWC) and the Department of Plant Resources (DPR) of government of Nepal for granting permission for sample collection.

\section{References}

Ainsworth E.A. and Gillespie K.M. 2007. Estimation of total phenolic content and other oxidation substrates in plant tissues using FolinCiocalteu reagent. Nature Protocols, 2: 875-877.

Andola H.C., Rawal R.S. and Bhatt I.D. 2008. Antioxidants in fruits and roots of Berberis asiatica Roxb. ex DC.: a highly valued Himalayan plant. National Academy of Science Letters, 31: $337-340$.

Andola H.C. 2012. Genus Berberis and berberine HPLC: an overview. Journal of Biologically Active Products from Nature, 2: 256-264.

Chandra S., Saklani S. and Alok S.S. 2011. Berberis asiatica future based excellent fruit in nutritional profile, antimicrobial and antioxidant ingredients. International Research Journal of Pharmacy, 2: 213-216.

Dashti Z., Shariatifar N. and Nafchi A. 2014. Study on antibacterial and antioxidant activity of Berberis vulgaris aqueous extracts from Iran. International Journal of Pharma Science and Research, 5: 705-708.

Eidi A., Zarin G.J., Rzazade S.A. and Adeli R. 2011. Hepatoprotective effects of Berberis vulgaris extract on $\mathrm{CCl}_{4}$ induced toxicity in rats. Trauma monthly, 16: 169-173.

Hanachi P., Kua S.H., Asmah R., Motalleb G. and Fauziah O. 2006. Cytotoxic effects of Berberis vulgaris fruit extract on the proliferation of human liver cancer line (HepG2) and its antioxidant properties. International Journal of Cancer Research, 21: 1-9.

Kamal Y.T., Singh M., Tamboli E.T., Parveen R. and Ahmad S. 2011. Quantitative analysis of berberine in Berberis aristata fruits and in a traditional anti-inflammatory Unani formulation by use of a validated HPLC method. Acta Chromatographica, 23: 157-168.

Koncic M.Z., Kremer D., Karlovic K. and Kosalec I. 2010. Evaluation of antioxidant activities and phenolic content of Berberis vulgaris L. and Berberis croatica Horvat. Food and Chemical Toxicology, 48: 2176-2180.

Meliani N., Dib M., Allali H. and Tabti B. 2011. Hypoglycaemic effect of Berberis vulgaris L. in normal and streptozotocin induced diabetic rats. Asian Pacific Journal of Tropical Biomedicine, 1: 468-471. 
Motalleb G., Hanachi P., Kua S.H., Fauziah O. and Asmah R. 2005. Evaluation of phenolic content and total antioxidant activity of Berberis vulgaris fruit extract. Journal of Biological Sciences, 5: 648-653.

Pal R.S., Kumar R., Agrawal P.K. and Bhatt J.C. 2013. Antioxidant capacity and related phytochemical analysis of methanolic extracts of two wild edible fruits from north western Indian Himalaya. International Journal of Pharma and Bio Sciences, 42: 113-123.

Perez C., Pauli M. and Bazerque P. 1990. An antibiotic assay by the agar well diffusion method. Acta Biologia et Medicine Experimentalis, 15: 113-115.

Rajaei Z., Hajzadeh M., Safiee S., Alvianenjhad A. and Samarghandian S. 2011. Effect of barberry fruit (Berberis vulgaris) on serum glucose and lipids in streptozotocin induced diabetic rats. Clinical Biochemistry, 44: S334 http://dx.doi.org/10.1016/j. clinbiochem.2011.08.825.

Rosenberg Zand R.S., Jenkins D.J.A. and Diamandis E.P. 2002. Flavonoids and steroid hormone dependent cancers. Journal of Chromatograrphy B, 777: 219-232.

Roy N., Laskar R.A., Sk I., Kumari D., Ghosh T. and Begum N.A. 2011. A detailed study on the antioxidant activity of the stem bark of Dalbergia sissoo Roxb., an Indian medicinal plant. Food Chemistry, 126: 1115-1121.

Saini R., Dangwal K., Singh H. and Garg V. 2014. Antioxidant and antiproliferative activities of phenolics isolated from fruits of Himalayan yellow raspberry (Rubus ellipticus). Journal of Food Science and Technology, 51: 3369-3375.

Seeram N.P. 2008. Berry fruits for cancer prevention: current status and future prospects. Agricultural Food Chemistry, 56: 630-635.
Semwal B.C., Gupta J., Singh S., Kumar Y. and Giri M. 2009. Antihyperglycemic activity of root of Berberis aristata DC. in alloxan-induced diabetic rats. International Journal of Green Pharmacy, 3: 259-263.

Shamsa F., Ahmadiani A. and Khosrokhavar R. 1999. Antihistaminic and anticholinergic activity of methanolic extract of barberry fruit (Berberis vulgaris) in the guinea pig ileum. Journal of Ethnopharmacology, 64: 161-166.

Singh J. and Kakkar P. 2009. Antihyperglycemic and antioxidant effect of Berberis aristata root extract and its role in regulating carbohydrate metabolism in diabetic rats. Journal of Ethnopharmacology, 123: 22-26.

Singh R.P., Murthy K.N.C. and Jayaprakasha G.K. 2002. Studies on antioxidant activity of pomegranate (Punica granatum) peel and seed extracts using in vitro models. Journal of Agricultural and Food Chemistry, 50: 81-86.

Soffar S.A., Metwali D.M., Abdel-Aziz S.S., El-Wakil H.S. and Saad G.A. 2001. Evaluation of the effect of a plant alkaloid (berberine derived from Berberis aristata) on Trichomonas vaginalis in vitro. Journal of the Egyptian Society of Parasitology, 31: 893-904.

Tiwari B.K. and Khosa R.L. 2010. Evaluation of the hepatoprotective and antioxidant effect of Berberis asiatica against experimentally induced liver injury in rats. International Journal of Pharmacy and Pharmaceutical Sciences, 2: 92-99.

Yao L.H., Jiang Y.M., Shi J., Tomas-Barberan F.A., Datta N., Singanusong R. and Chen S.S. 2004. Flavonoids in food and their health benefits. Plant Foods for Human Nutrition, 59: 113-122. 